\title{
Penggunaan Metode Unsupervised (ISO Data) untuk Mengkaji Kerapatan Vegetasi di Kecamatan Pangandaran
}

\author{
Agung Dwi Rahmawan ${ }^{1 *}$, Dini Adha Pawestri ${ }^{1}$, Rafifah Adinda Fakhriyah ${ }^{1}$, Habibie \\ Daud Syafaat Pasha ${ }^{1}$, Muhamad Ferryandy ${ }^{1}$, Dede Sugandi ${ }^{1}$, Riki Ridwana ${ }^{1}$, Lili \\ Somantri ${ }^{1}$
}

1Program Studi Pendidikan Geografi, Departemen Pendidikan Geografi, Universitas Pendidikan Indonesia, Indonesia

\author{
A R T I C L EI N F O \\ Article history: \\ Received 28 December \\ 2019 \\ Accepted 07 February \\ 2020 \\ Available online 30 \\ April 2020 \\ Kata Kunci: \\ Pengindraan Jauh; \\ Metode Unsupervised; \\ Kerapatan Vegetasi \\ Keywords: \\ Remote sensing; \\ Unsupervised Method; \\ Vegetation Density
}

\begin{abstract}
A B S T R A K
Pengindraan jauh saat ini sudah mulai dikembangkan dan dimanfaatkan untuk berbagai bidang keilmuan. Penelitian ini dilakukan dengan menggunakan metode pengindraan jauh) di Kecamatan Pangandaran untuk mengetahui kesesuaian kerapatan vegetasi dengan hasil interpretasi. Menggunakan citra Landsat 8 dengan metode Unsupervised Classification Iso Data dan dalam pengolahannya menggunakan software Envi 5.0 dan Arcgis 10.4. Analisis yang digunakan yaitu analisis spasial dan membandingkan hasil interpretasi dengan hasil data di lapangan, dan melakukan uji akurasi. Uji akurasi dilakukan untuk menemukan besaran kesesuaian metode dengan data yang dilakukan. Maka akan dapat diketahui bahwa metode klasifikasi yang digunakan kurang tepat untuk mengidentifikasi kerapatan vegetasi karena memiliki banyak data yang tidak sesuai dengan yang ada di lapangan. Dengan mengidentifikasi kerapatan vegetasi, maka dapat membantu mengetahui perencanaan ruang terbuka hijau yang tepat untuk wilayah kecamatan Pangandaran.
\end{abstract}

\begin{abstract}
A B S T R A C T
Remote sensing has now begun to be developed and utilized for various scientific fields. This research was conducted using the remote sensing method) in Pangandaran District to determine the suitability of vegetation density with the results of interpretation. It is using Landsat 8 imagery using the Iso Data Unsupervised Classification method and in its processing using Envi 5.0 and Arcgis 10.4 software. The analysis used in spatial analysis and comparing the results of interpretation with the results of data in the field and conducting accuracy tests. An accuracy test is performed to find the magnitude of the suitability of the method with the data presented. Then it will be known that the classification method used is not appropriate to identify the density of vegetation because it has many data that do not match those in the field. By identifying the density of vegetation, it can be helped to find out the right the urban open space planning for the Pangandaran sub-district.
\end{abstract}

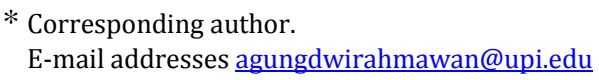




\section{Pendahuluan}

Indonesia memiliki vegetasi yang beragam dengan banyak hutan hujan tropis karena letak Indonesia yang berada pada lintang tropis yaitu $6^{\circ} \mathrm{LU}-11^{\circ} \mathrm{LS}$, dan $95^{\circ} \mathrm{BT}-141^{\circ} \mathrm{BT}$ yang menyebabkan Indonesia mendapatkan sinar matahari sepanjang tahun, dan hanya mempunyai dua musim yaitu musim panas pada April - Agustus dengan puncak musim panas pada bulan Juli - Agustus dan musim hujan pada September - Maret dengan puncak musim hujan pada bulan November - Desember (Aftriana, 2013; Alizadeh \& Hitchmough, 2019).

Kecamatan Pangandaran yang merupakan salah satu kecamatan dari 10 kecamatan yang ada di Kabupaten Pangandaran. Mempunyai luas wilayah sebesar $1.680 \mathrm{~km}^{2}$, dan memiliki luas hutan sebesar 6.342 ha. Vegetasi yang berada di Kecamatan Pangandaran didominasi oleh vegetasi Mangrove karena berada di pesisir pantai dengan suhu rata-rata $24^{\circ} \mathrm{C}$. Tingkat kerapatan yang ada di Kecamatan Pangandaran di dominasi oleh Vegetasi Rapat yang tersebar di hampir seluruh wilayah. Namun, Kecamatan Pangandaran juga memiliki jenis Vegetasi Sangat Rapat yang cukup banyak salah satunya berada di Cagar Alam. Cagar Alam yang berada di Kecamatan Pangandaran didominasi oleh kerapatan vegetasi Rapat hingga Sangat Rapat (Kurniawan, Tapilouw, Hidayat, \& Setiawan, 2019; Kusmana \& Ningrum, 2016).

Interpretasi citra adalah kegiatan mengkaji objek pada foto udara atau citra untuk menilai pentingnya objek tersebut. Interpretasi citra dilakukan melalui 3 (tiga) tahapan yaitu deteksi, identifikasi, dan analisis. Deteksi merupakan pengenalan awal dengan melihat foto udara atau citra secara keseluruhan. Identifikasi merupakan pembacaan ciri-ciri (spektral, spasial, dan temporal) dari setiap objek. Analisis merupakan penguraian dan pengklasifikasian data hasil identifikasi sehingga menghasilkan bentuk tabel, grafik dan peta tematik.

Metode klasifikasi citra yang digunakan sangat menentukan hasil dari klasifikasi citra, dengan demikian persoalan pemetaan menggunakan data pengindraan jauh digital adalah pemilihan metode klasifikasi yang digunakan dalam klasifikasi citra (Apriyanti, Nugroho, \& Soesanto, 2016; Lufilah, Makalew, \& Sulistyantara, 2017). Metode untuk memperoleh informasi dari data pengindraan jauh yang paling sering digunakan ialah klasifikasi multispektral berdasarkan analisis terhadap reflektansi. Klasifikasi multispektral yang sudah digunakan secara luas, yang salah satunya untuk memetakan kerapatan vegetasi, penutupan lahan dan geomorfologi yang dilaksanakan pada praktikum Pengindraan Jauh pada akhir November sampai awal Desember lalu di Kecamatan Pangandaran yang dilaksanakan oleh Universitas Pendidikan Indonesia angkatan 2018 program studi Pendidikan Geografi.

Klasifikasi citra multispektral dilakukan menggunakan dua metode klasifikasi yaitu supervised classification dan unsupervised classification. Keunggulan unsupervised classification adalah kesalahan operator diminimalisir dan unique class dianggap sebagai distinct units (Cahyono, Febriawan, \& Nugroho, 2019; Septiani, Citra, \& Nugraha, 2019). Kekurangannya adalah korespondensi yang tidak jelas terhadap informational classes, kontrol terbatas terhadap classes, dan spatial classes tidak konstan. Penelitian ini menggunakan metode unsupervised classification yaitu ISODATA dan K-Means. Metode K-Means memiliki keunggulan dalam proses pengklasifikasian karakteristik objek dan tidak terpengaruh terhadap urutan objek yang digunakan dan metode ISODATA memiliki keunggulan dalam proses iterasinya.

Ruang terbuka hijau merupakan area memanjang/jalur dan/atau mengelompok yang penggunaannya lebih bersifat terbuka, tempat tumbuh tanaman, baik yang tumbuh secara alamiah maupun yang sengaja ditanam. Peraturan menteri pekerjaan umum tahun 2008 menyatakan bahwa kuantitas dan kualitas ruang terbuka publik terutama ruang terbuka hijau (RTH) saat ini mengalami penurunan yang sangat signifikan dan mengakibatkan penurunan kualitas lingkungan hidup perkotaan yang berdampak berbagai sendi kehidupan perkotaan antara lain sering terjadinya banjir, peningkatan pencemaran udara, dan menurunnya produktivitas masyarakat akibat terbatasnya ruang yang tersedia untuk interaksi sosial (Schwartz, Taff, Lawhon, \& VanderWoude, 2018).

Pemahaman terhadap hubungan antara penyelenggaraan pemukiman dengan perencanaan kawasan wilayah yang fungsional dan responsif terhadap perkembangan dan permasalahan yang dihadapi saat ini diharapkan dapat menciptakan keseimbangan antara pembangunan di kawasan perkotaan dan kawasan sekitarnya, sehingga kawasan perkotaan dapat lebih terjaga. Penurunan luasan lahan pertanian dari 2.136 ha menjadi $1.417 \mathrm{Ha}$ turun dengan laju rata-rata 12,4\% per tahun yang disebabkan oleh alih fungsi lahan. Alih fungsi kawasan vegetasi menjadi kawasan terbangun mengakibatkan keseimbangan ekologi kota berkurang. Vegetasi pada area perkotaan sangat mempengaruhi udara sekitarnya secara langsung maupun tidak langsung dengan berubahnya kondisi atmosfer lingkungan.

Penggunaan metode NDVI (Normalized difference Vegetatioon Index) dan metode SAVI (Soil Adjusted Vegetation Index) digunakan untuk mengetahui persebaran ruang terbuka hijau yang digunakan untuk perhitungan perubahan ruang terbuka hijau. Berdasarkan permasalahan di atas, maka penting 
dilakukannya analisis terhadap perubahan ruang terbuka hijau dengan penggunaan teknologi pengindraan jauh yang efektif. Penginderaan jauh didasarkan pada satuan pengamatan terkecil berupa piksel. Apabila dalam satu piksel dijumpai berbagai tipe tutupan lahan, maka dianggap mewakili tutupan lahan tertentu, yang secara rata-rata lebih menonjol jumlahnya dari pada tipe lainnya. Misalkan piksel tersebut dianggap sebagai lahan terbangun yang di dalamnya terdapat RTH, lahan terbangun dan badan air (Faisal \& Atmaja, 2019; Thorne, Santos, \& Bjorkman, 2013; Threlfall et al., 2016).

Ruang terbuka hijau di daerah perkotaan sangat dibutuhkan. Karena, tingginya suhu udara di dearah perkotaan yang disebabkan oleh banyaknya kendaraan bermotor yang mengeluarkan asap, banyaknya didirikan pabrik-pabrik, gedung yang sangat tingi, hal tersebut merupakan beberapa penyebab mengapa harus memperbanyak ketersediaan ruang terbuka hijau di daerah perkotaan. Dampak dari hal-hal tersebut sangat kurang baik untuk kehidupan manusia. Banyak sekali kerugian yang ditimbulkan. Beberapa di antaranya yakni kesehatan manusia menjadi terganggu, suhu udara semakin panas atau tinggi, hal tersebut dirasa kurang begitu nyaman untuk makhluk hidup yang tinggal di daerah perkotaan tersebut. Pada dasarnya manusia menginginkan hidup dengan udara yang sejuk, nyaman, dan sehat. Oleh karena itu, ruang terbuka hijau harus diperbanyak ketersediaannya. Selain itu, ruang terbuka hijau dapat menjadi daerah resapan air ketika terjadi hujan sehingga tidak menyebabkan banjir.

Pengindraan jauh merupakan ilmu pengetahuan untuk menganalisis suatu obyek tanpa harus melakukan kontak langsung dengan obyek tersebut. Sebagian besar sistem pengindraan jauh adalah pasif. Sistem tersebut menggunakan gelombang pendek dari energi elektromagnetik yang langsung dipantulkan oleh matahari. Ada juga sistem aktif. Dikatakan sistem yang aktif apabila diperoleh citra secara buatan oleh sensor pengindraan jauh, misalnya radar.

Berdasarkan paparan yang telah dikemukakan, yang menjadi tujuan penelitian ini yaitu (1) mendeskripsikan hasil klasifikasi kerapatan vegetasi di Kecamatan Pangandaran dari Citra Landsat 8 menggunakan metode unsupervised classification, (2) menghitung tingkat akurasi dari terhadap kerapatan vegetasi di Kecamatan Pangandaran. Dengan diadakannya penelitian interpretasi citra dan groundcheck ini adalah untuk melatih mahasiswa khususnya mahasiswa Pendidikan Geografi angkatan 2018 dalam membuat peta tematik digital dengan bantuan aplikasi ArcGis dan ENVI yang hasilnya dievaluasi kembali melalui groundcheck pada daerah yang telah dipetakan sebelumnya.

\section{Metode}

\section{Lokasi dan Waktu Penelitian}

Penelitian ini dilaksanakan pada tanggal 30 November - 1 Desember 2019, di Kecamatan Pangandaran, Kabupaten Pangandaran, Provinsi Jawa Barat. Secara geografis terletak pada 070 42' 06" LS - $108^{0} 29^{\prime} 41^{\prime \prime}$ BT. Kecamatan Pangandaran memiliki luas area $1.680 \mathrm{~km}^{2}$. Kecamatan Pangandaran adalah salah satu dari 10 kecamatan yang ada di Kabupaten Pangandaran. Kecamatan Pangandaran terletak di bagian paling selatan dari Kabupaten Pangandaran dan merupakan daerah wisata utama di Kabupaten Pangandaran.

Kabupaten Pangandaran adalah sebuah kabupaten di Provinsi Jawa Barat dengan ibu kota Parigi. Kabupaten ini berbatasan dengan Kabupaten Ciamis dan Kota Banjar di utara, Kabupaten Cilacap di timur, Samudera Hindia di selatan, serta Kabupaten Tasikmalaya di barat.

Kecamatan Pangandaran dipilih sebagai tempat pelaksanaan penelitian karena merupakan salah satu tempat wisata yang ada di Jawa Barat. Pada Pantai Pangandaran juga terdapat sebuah daratan yang menjorok ke laut yang sekarang menjadi cagar alam atau hutan lindung. Oleh karena itu, tempat ini juga sangat cocok untuk melaksanakan penelitian mengenai kerapatan vegetasi.

\section{Sumber data}

Penelitian ini menggunakan citra Landsat 8 Pangandaran, resolusi 25 x 25 m yang diambil pad tahun 2019 dan diperoleh dari The US Geological Survey (USGS). Kemudian, data dioleh menggunakan perangkat lunak ArcMap 10.4, Envi 5.3, Global Positioning System (GPS), kamera digital, pita ukur, instrumen kerapatan vegetasi, Avenza Map 3.8 dan fish eye camera.

\section{Pengamatan Data Lapangan}

Pengambilan data di lapangan di awali dengan membuat 10 - 15 plot yang dilakukan di basecamp dengan jarak kurang lebih 300 meter masing-masing plot. Penentuan plot berdasarkan dengan kelas vegetasi yang ada. Pengamatan vegetasi dilakukan dengan mendatangi plot yang telah ditentukan dan melakukan groundcheck, kemudian mengambil dokumentasi foto dengan kamera digital, dokumentasi dengan fish eye untuk mengetahui tingkatan kerapatan dari arah Barat, Timur, Selatan, Utara dan Tengah 
dari plot yang telah ditentukan. Pada pengamatan data lapangan juga melakukan pengukuran sejauh 7,5 meter ke arah Barat, Timur, Selatan dan Utara dari plot yang telah ditentukan.

\section{Pengolahan Citra}

Penyusunan citra komposit warna adalah cara yang paling umum untuk menonjolkan masingmasing keunggulan saluran secara serentak dalam suatu display, sehingga memudahkan pengguna dalam interpretasi citra secara visual. Citra ini merupakan perpaduan 3 saluran, dengan masing-masing saluran diberi warna dasar, yaitu merah, hijau, dan biru (RGB). Warna yang terjadi adalah kombinasi dari tingkat kecerahan pada suatu obyek di setiap saluran.

Citra komposit standar merupakan paduan tiga saluran/ band, dengan masing-masing saluran diberi warna biru untuk band 2, warna hijau untuk band 3, dan warna merah untuk band 4, sehingga menghasilkan citra komposit true color (warna objek sebenarnya). Penggunaan komposit citra untuk berbagai aplikasi atau penelitian dapat dilihat pada tabel di bawah ini.

Tabel 1.

Penggunaan Citra Komposit

\begin{tabular}{lc}
\hline \multicolumn{1}{c}{ Aplikasi } & Komposit Band \\
\hline Natural Color & 432 \\
False Color (urban) & 764 \\
Color Infrared (vegetation) & 543 \\
Agriculture & 652 \\
Atmospheric Penetration & 765 \\
Healthy Vegetation & 564 \\
Natural with Atmospheric Removal & 753 \\
Shortwave Infrared & 754 \\
Vegetation Analysis & 654 \\
\hline
\end{tabular}

\section{Klasifikasi Metode}

Penelitian ini menggunakan software Pengindraan Jauh yaitu Envi 5.0 dan Arcgis 10.4, dan mengklasifikasikan citra multispektral klasifikasi unsupervised (klasifikasi tak terbimbing) dengan algoritma Iso Data.

Cara kerja metode ini adalah mengelompokkan nilai-nilai piksel dengan komputer ke dalam kelas spektral menggunakan algoritma klusterisasi. Dalam metode ini, di awal proses analisis biasanya akan menentukan jumlah kelas (cluster) yang akan dibuat. Kemudian, setelah mendapatkan hasil, analisis menetapkan kelas-kelas objek terhadap kelas-kelas spektral yang telah dikelompokkan oleh komputer. Dari kelas-kelas (cluster) yang dihasilkan, analisis bisa menggabungkan beberapa kelas yang dianggap memiliki informasi sama menjadi satu kelas. Misalnya, class 1, class 2, dan class 3 adalah hutan, perkebunan, sawah. Maka, analisisnya bisa dikelompokkan menjadi satu kelas yaitu kelas vegetasi. Jadi, pada metode ini tidak terdapat campur tangan manusia.

Jadi, algoritma Iso Data adalah mengklasifikasikan kelas secara merata. Piksel-piksel diklasifikasikan ke kelas terdekat. Setiap iterasi kalkulasi ulang sarana dan mereklasifikasi piksel sehubungan dengan cara baru iteratif membelah kelas, penggabungan, dan menghapus dilakukan berdasarkan parameter include threshold. Semua piksel diklasifikasikan ke kelas terdekat kecuali deviasi standar atau ambang batas jarak yang telah ditentukan. Dalam hal ini, beberapa piksel mungkin unclassified jika mereka tidak memenuhi kriteria yang dipilih. Proses ini berlanjut sampai jumlah piksel dalam setiap perubahan kelas kurang dari ambang perubahan piksel yang dipilih atau jumlah maksimum iterasi tercapai.

\section{Hasil dan pembahasan}

\section{Pembuatan Citra Komposit.}

Interpretasi Citra Landsat 8 terhadap klasifikasi kerapatan vegetasi dengan kombinasi band 432 menggunakan metode Unsupervised Classification (ISODATA). Kelas kerapatan vegetasi teridentifikasi menjadi 5, yaitu vegetasi jarang, rapat, cukup rapat, sangat rapat dan badan air. Pemilihan citra komposit RGB (432) atau citra Natural Colour, hal ini dikarenakan pada komposit band ini dapat menonjolkan vegetasi dengan warna hijau yang jelas, tanah atau lahan kosong dengan warna coklat cerah dan juga 
badan air dengan warna biru agak gelap. Sehingga dengan komposit band tersebut dapat memudahkan dalam menginterpretasi kerapatan vegetasi. Pengolahan Citra Komposit. Citra ini adalah perpaduan 3 saluran, dengan masing-masing saluran diberi warna dasar, yaitu merah, hijau, dan biru (RGB). Warna yang terjadi adalah kombinasi dari tingkat kecerahan pada suatu obyek di setiap saluran. Citra komposit standar merupakan paduan tiga saluran/band, dengan masing-masing saluran diberi warna biru untuk band 2, warna hijau untuk band 3, dan warna merah untuk band 4, sehingga menghasilkan citra komposit Natural Colour (warna objek sebenarnya). Selanjutnya kita menggunakan metode ISODATA untuk menentukan klaster kerapatan vegetasi yang ada pada citra yang dengan menentukan jumlah kelas yang ada. Klasifikasi ini menggunakan teknik jarak minimum semua piksel yang diklasifikasikan ke kelas terdekat kecuali deviasi standar atau ambang batas jarak yang ditentukan, dalam ini mungkin ada beberapa piksel yang mungkin akan unclassified jika mereka tidak memenuhi kriteria yang ditentukan proses ini berlanjut sampai jumlah piksel dalam setiap perubahan kelas kurang dari ambang perubahan piksel yang dipilih atau jumlah maksimum iterasi tercapai.

Interpretasi Penyebaran Vegetasi. Dalam kegiatan Interpretasi Kerapatan Vegetasi dan Hasil Data Lapangan Kerapatan Vegetasi yang dilakukan di Kecamatan Pangandaran mendapatkan hasil sebagai berikut

Tabel 2.

Hasil Interpretasi Kerapatan Vegetasi

\begin{tabular}{cc}
\hline Hasil Interpretasi Kerapatan & Jumlah Sampel \\
Vegetasi & 1 \\
Cukup Rapat & 4 \\
Sangat Rapat & 3 \\
Rapat & 2 \\
Vegetasi Jarang & 10 \\
Total Sampel & \\
\hline
\end{tabular}

Tabel 3

Hasil Data Lapangan Kerapatan Vegetasi

$\begin{array}{ccc} & \text { Hasil Data Lapangan Kerapatan } & \text { Jumlah Sampel } \\ & \text { Vegetasi } & 2 \\ & \text { Cukup Rapat } & 2 \\ \text { Sangat Rapat } & 1 \\ \text { Rapat } & 4 \\ \text { Vegetasi Jarang } & 10 \\ \text { Tori tabel } & \text { Total Sampel } & \end{array}$

hasil dari interpretasi kerapatan vegetasi dan hasil data lapangan kerapatan vegetasi. Dalam penelitian ini didapatkan bahwa pada citra yang diolah dan data yang ada di lapangan ternyata terdapat perbedaan. Pada hasil dari interpretasi kerapatan vegetasi terdapat 1 sampel cukup rapat, 4 sampel sangat rapat, 3 sampel rapat, dan 2 sampel vegetasi jarang. Sedangkan hasil data lapangan kerapatan vegetasi terdapat 2 sampel cukup rapat, 2 sampel sangat rapat, 1 sampel rapat, dan 4 sampel vegetasi jarang.

\section{Indeks Vegetasi dengan NDVI}

Indeks vegetasi adalah besaran nilai kehijauan vegetasi yang diperoleh dari pengolahan sinyal digital data nilai kecerahan (brightness) beberapa kanal data sensor satelit. Untuk pemantauan vegetasi, dilakukan proses pembandingan antara tingkat kecerahan kanal cahaya merah (red) dan kanal cahaya inframerah dekat (near infrared). Fenomena penyerapan cahaya merah oleh klorofil dan pemantulan cahaya inframerah dekat oleh jaringan mesofil yang terdapat pada daun akan membuat nilai kecerahan yang diterima sensor satelit pada kanal-kanal tersebut akan jauh berbeda. Pada daratan non-vegetasi, termasuk di antaranya wilayah perairan, pemukiman penduduk, tanah kosong terbuka, dan wilayah dengan kondisi vegetasi yang rusak, tidak akan menunjukkan nilai rasio yang tinggi (minimum).

Sebaliknya pada wilayah bervegetasi sangat rapat, dengan kondisi sehat, perbandingan kedua kanal tersebut akan sangat tinggi (maksimum). Nilai perbandingan kecerahan kanal cahaya merah dengan cahaya inframerah dekat atau NIR/RED, adalah nilai suatu indeks vegetasi (yang sering disebut "simple 
ratio") yang sudah tidak dipakai lagi. Hal ini disebabkan karena nilai dari rasio NIR/RED akan memberikan nilai yang sangat besar untuk tumbuhan yang sehat (Prasetyo, Sasmito, \& Prasetyo, 2017).

Pada tumbuhan sehat, pemantulan cahaya inframerah dekat (near infrared) akan terjadi secara signifikan pada rentang spektrum antara $0.7 \mu \mathrm{m}$ hingga $1.2 \mu \mathrm{m}$. Hanya sedikit energi infrared ini yang terserap oleh struktur daun. Sebagian besar akan terhamburkan ke atas (reflected energy) dan ke bawah daun (transmitted energy). Pada daun yang sehat umumnya mempunyai pemantulan cahaya sebesar $40 \%$ $60 \%$, transmisi cahaya sebesar $40 \%-60 \%$, dan penyerapan relatif sebesar $5 \%-10 \%$.

Tampak bahwa penyerapan terbesar berada pada kanal cahaya biru dan merah. Persentase refleksi cahaya inframerah dekat $(0.7-1.2 \mu \mathrm{m})$ oleh daun disebabkan karena penghamburan internal pada sisi dinding sel dalam daun. Namun, besar persentasi refleksi ini berkurang pada rentang frekuensi 0.92-0.98 $\mu \mathrm{m}$. Hal ini disebabkan karena uap air mempunyai karakteristik penyerapan cahaya pada rentang frekuensi tersebut. Oleh karena itu, rentang sepektrum cahaya inframerah dekat yang optimal digunakan oleh aplikasi pengindraan jarak jauh berkisar antara $0.74 \mu \mathrm{m}$ hingga $0.9 \mu \mathrm{m}$ saja.

Metode yang digunakan dalam kasus ini adalah metode NDVI (Normalized Difference Vegetation Index). Adapun yang dimaksud NDVI adalah nilai dari hasil pengelolaan dari indeks vegetasi citra satelit kanal merah dan kanal infra merah yang menunjukkan konsentrasi dari klorofil daun yang berkolerasi dengan kerapatan vegetasi (Gowda, Sridhara, \& Rajan, 2008). Berikut adalah indeks NDVI yang digunakan untuk menganalisis kerapatan vegetasi pada Kecamatan Pangandaran.

Tabel 4 .

Klasifikasi NDVI

\begin{tabular}{lll}
\hline Range Klasifikasi & Tingkat Kerapatan & Contoh Jenis Vegetasi \\
\hline$-1-0$ & Badan Air & - \\
$0-0,25$ & Vegetasi Jarang & Pemukiman, lahan kosong \\
$0,25-0,55$ & Cukup Rapat & Sawah, tegalan \\
$0,55-0,78$ & Rapat & Sawah, semak belukar \\
$0,78-1$ & Sangat Rapat & Hutan \\
\hline
\end{tabular}

\section{Uji Akurasi Kerapatan Vegetasi}

Uji akurasi dilakukan untuk memvalidasi hasil analisis digital yang telah dilakukan dengan pengukuran atau hasil data yang dilakukan di lapangan. Salah satu cara yang dapat dilakukan untuk uji akurasi adalah dengan menggunakan matriks kesalahan. Tabel matriks kesalahan tidak hanya digunakan untuk memperoleh akurasi seluruh kategori, tetapi juga akurasi tiap-tiap kategori.

Tabel 5.

Matriks Kesalahan ISO DATA

\begin{tabular}{llccccc}
\hline & \multicolumn{5}{c}{ HASIL INTERPRETASI } \\
\hline \multirow{2}{*}{\begin{tabular}{c} 
Obyek \\
\cline { 2 - 6 }
\end{tabular}} & $\begin{array}{c}\text { Cukup } \\
\text { Rapat }\end{array}$ & Sangat Rapat & Rapat & $\begin{array}{c}\text { Vegetasi } \\
\text { Jarang }\end{array}$ & Jumlah \\
\cline { 2 - 7 } & Cukup Rapat & 0 & 0 & 2 & 1 & 3 \\
Sangat Rapat & 0 & 2 & 0 & 0 & 2 \\
Rapat & 0 & 0 & 1 & 0 & 1 \\
Vegetasi & 1 & 2 & 0 & 1 & 4 \\
Jarang & 1 & 4 & 3 & 2 & 10 \\
\hline
\end{tabular}

Angka dalam matriks diagonal merupakan hasil klasifikasi dan data lapangan yang benar atau sesuai. Apabila angka-angka pada diagonal utama tersebut dijumlahkan dan kemudian dibagi dengan jumlah sampel maka akan didapatkan akurasi seluruh kategori. Berdasarkan tabel di atas, ketelitian seluruh kategori adalah:

$$
\text { Akurasi Jumlah Kategori }=\frac{0+2+1+1}{10}=\frac{4}{10}=40 \%
$$


Ketelitian pemetaan suatu kelas tergantung pada pembuat peta dan pengguna peta, serta mempertimbangkan kesalahan hapusan (omisi) dan kesalahan imbuhan (komisi). Berdasarkan akurasi jumlah kategori, perhitungan akurasi penghasil peta dan pengguna peta adalah:

Tabel 6.

Hasil Akurasi Penghasil dan Pengguna Peta

\begin{tabular}{lcccc}
\hline \multirow{2}{*}{ Kelas } & \multicolumn{2}{c}{ Akurasi Pembuat Peta } & \multicolumn{2}{c}{ Akurasi Pengguna Peta } \\
\cline { 2 - 5 } & Akurasi & Komisi & Akurasi & Omisi \\
\hline Cukup Rapat & $0 / 1=0 \%$ & $100 \%$ & $0 / 3=0 \%$ & $100 \%$ \\
Sangat Rapat & $2 / 4=50 \%$ & $50 \%$ & $2 / 2=100 \%$ & $0 \%$ \\
Rapat & $1 / 3=33,3 \%$ & $66,7 \%$ & $1 / 1=100 \%$ & $0 \%$ \\
Vegetasi Jarang & $1 / 2=50 \%$ & $50 \%$ & $1 / 4=25 \%$ & $75 \%$ \\
\hline
\end{tabular}

\section{Keadaan Vegetasi}

Keadaan vegetasi wilayah Kecamatan Pangandaran didominasi oleh ekologi tanaman pantai. Pada lokasi pertama yang kami amati yaitu pada desa Purbahayu, vegetasi didominasi oleh hutan jati yang berada di hampir seluruh kawasan. Terdapat tanaman khas wilayah pantai yaitu kelapa yang juga cukup banyak ditemui didaerah tersebut. Karena hampir didominasi oleh jenis vegetasi jarang maka lebih banyak rumah daripada tumbuhan yang dapat ditemukan, tumbuhan yang dapat ditemukan yaitu pohon mangga, pohon salak, pohon jambu, pohon pisang, talas, nanas, jahe, dan singkong.

Pada lokasi pengamatan kedua di sekitar pantai dan cagar alam, ditemukan jenis tumbuhan yang didominasi magrove pada pesisir pantai. Sedangkan pada Cagar Alam Pananjung Pangandaran terdapat sekitar $80 \%$ merupakan vegetasi hutan sekunder tua dan sisanya adalah hutan primer. Pohon yang mendominasi antara lain Laban (Vitex pubescens), Kisegel (Dilenia excelsea), dan Marong (Cratoxylon formosum). Selain itu banyak juga terdapat jenis pohon seperti Reungas (Buchanania arborences), Kondang (Ficus variegata), Teureup (Artocarpus elastica), dan lain-lain. Pada dataran rendahnya terdapat hutan tanaman yang merupakan tanaman exotica, yaitu tanaman jati (Tectona grandis), Mahoni (Swietenia mahagoni), dan Komis (Acacia auriculuformis).

\section{Analisis Keterkaitan Vegetasi dengan Ruang Terbuka Hijau}

Ruang terbuka hijau merupakan sebuah ruang dengan fungsi ekologis yang sering kali dikorbankan dalam membangun dan mengembangkan sebuah kota. Ruang terbuka hijau (RTH) memiliki fungsi antara lain sebagai area rekreasi, sosial budaya, estetika, fisik, kota, ekologis, dan memiliki nilai ekonomis yang cukup tinggi bagi manusia maupun bagi pengembangan kota (Dewiyanti, 2009).

Penetapan luas RTH diatur dalam rencana induk sebagaimana dimaksud pada ayat (2) huruf b angka 1 paling sedikit 30\% (tiga puluh perseratus) dari luasan wilayah perkotaan. Dalam hal ini Analisis kebutuhan RTH sesuai dengan pola sebaran sub wilayah kota yang terdiri atas : (1) penetapan luas RTH; (2) jenis dan kriteria Vegetasi; (3) elemen estetika pendukung RTH. Hal ini menunjukkan bahwa ruang terbuka hijau memiliki keterkaitan yang kuat dengan vegetasi. Pemerintah Pangandaran sendiri telah membuka berbagai ruang terbuka hijau seperti yang ada di daerah Parigi.

Berdasarkan peta yang telah dibuat, kecamatan Pangandaran memiliki tingkat vegetasi yang didominasi oleh vegetasi rapat dan beberapa vegetasi jarang. Namun, pada kondisi di lapangan, kerapatan vegetasi yang ada di kecamatan Pangandaran lebih banyak di dominasi oleh Vegetasi Jarang seperti pemukiman, hotel, dan tempat rekreasi lainnya. Hal ini didukung dengan adanya dijadikannya kecamatan Pangandaran sebagai "Kawasan Wisata", dengan begitu maka pemerintah terus meningkatkan pembangunan fisik yang berada di wilayah kecamatan Pangandaran, maka dari itu banyak data yang tidak sesuai antara hasil interpretasi dengan keadaan di lapangan. Perubahan kecamatan Pangandaran sangat signifikan, hal itu terlihat dari banyaknya tempat penginapan yang dibangun secara terus-menerus tanpa mementingkan resapan air yang ada dan juga membuat lingkungan semakin tercemar seiring dengan banyaknya turis yang juga dapat menyebabkan polusi udara. Maka dari itu, interpretasi dari kerapatan vegetasi yang berada di kawasan Pangandaran dapat membantu untuk merencanakan pembangunan 
ruang terbuka hijau (RTH) karena merupakan hal yang sangat penting bagi kelangsungan ekosistem yang ada dan agar lingkungan dapat terjaga keseimbangannya dengan baik (McCord et al., 2014).

Vegetasi dan tanah di ruang hijau perkotaan menentukan kapasitas lingkungan perkotaan untuk mendukung keanekaragaman hayati menurut pandangan tersebut, berarti vegetasi dan ruang terbuka hijau (RTH) mendukung keanekaragaman hayati, kecamatan Pangandaran sendiri memiliki berbagai jenis flora dan fauna yang melimpah. Jika RTH tidak dijaga dengan baik, maka keanekaragaman hayati akan terancam punah. Oleh karena itu, pemerintah selain harus memperhatikan pembangunan fisik berupa bangunan juga harus lebih mementingkan lagi pembangunan ruang terbuka hijau di kecamatan Pangandaran. Memahami sifat dan variabilitas vegetasi dalam jaringan ruang hijau dapat membantu menginformasikan pengetahuan kita tentang distribusi layanan ekosistem yang disediakannya dan komposisi komunitas fauna yang bergantung padanya. Ini juga dapat membantu memprioritaskan manajemen strategis vegetasi ruang hijau perkotaan sehingga memberikan manfaat terbesar bagi manusia dan keanekaragaman hayati (Ardhana, 2016). Dari pandangan tersebut, maka pemerintah juga seharusnya mengetahui jenis vegetasi yang diprioritaskan dalam membangun ruang terbuka hijau, hal ini sangat penting karena jika tidak seperti itu, maka ruang terbuka hijau memiliki manfaat yang kurang maksimal. Dengan mengetahui jenis vegetasi yang harus diprioritaskan, dengan begitu manfaat RTH bagi masyarakat sekitar akan lebih dirasakan manfaatnya dengan baik atau bahkan dapat menambah perekonomian masyarakat, serta membantu keseimbangan ekosistem. Vegetasi dan tanah ruang hijau juga merupakan komponen yang paling mudah dimanipulasi oleh manusia melalui gangguan dan tindakan pengelolaan langsung (Threlfall et al., 2016). Hal ini berarti setelah ruang terbuka hijau tercukupi jumlahnya yaitu sekitar $30 \%$ langkah berikutnya yang harus dilakukan pemerintah dan masyarakat adalah dengan merawat RTH tersebut dengan baik, karena vegetasi dan ruang terbuka hijau sangat mudah berubah akibat pengaruh manusia secara langsung (Sinaga, Suprayogi, \& Haniah, 2018; Tufaila, Karim, \& Alam, 2012; Wulansari, 2018).

\section{Analisis Kerapatan Vegetasi Kecamatan Pangandaran}

Berdasarkan hasil pengamatan dengan menggunakan metode Unsupervised Classified (ISODATA), keakuratan metode ini cukup rendah dengan nilai persentase $40 \%$. Adanya ketidaksesuaiaan data pada beberapa sampel yang kita amati di lapangan dengan data yang ada pada citra yang kami pakai. Berdasarkan interpretasi dari citra, hanya ada 1 sampel kelas vegetasi yang cukup rapat, tetapi pada kenyataan di lapangan ada 3 sampel kelas vegetasi yang cukup rapat. Lalu pada kelas vegetasi yang sangan rapat pada hasil interpretasi citra ada 4 sampel, tetapi pada kenyataan di lapangan hanya ada 2 sampel, dan seterusnya seperti yang tercantum pada tabel di atas. Ini menunjukkan bahwa keakuratan metode yang kami pakai cukup rendah karena adanya ketidaksesuiaan data hasil interpretasi citra dengan kenyataan yang ada di lapangan. Sehingga disarankan kepada pengamat atau analis selanjutnya agar tidak menggunakan metode ini karena tingkat akurasi atau keakuratannya yang cukup rendah dan tidak cocok untuk pengamatan kerapatan vegetasi.

Dengan kegiatan pengecekan lapangan atau groundcheck yang telah kami lakukan di Kecamatan Pangandaran dan Cagar Alam Panunjung dengan 10 plot yang kami dapatkan adalah sebagai berikut:

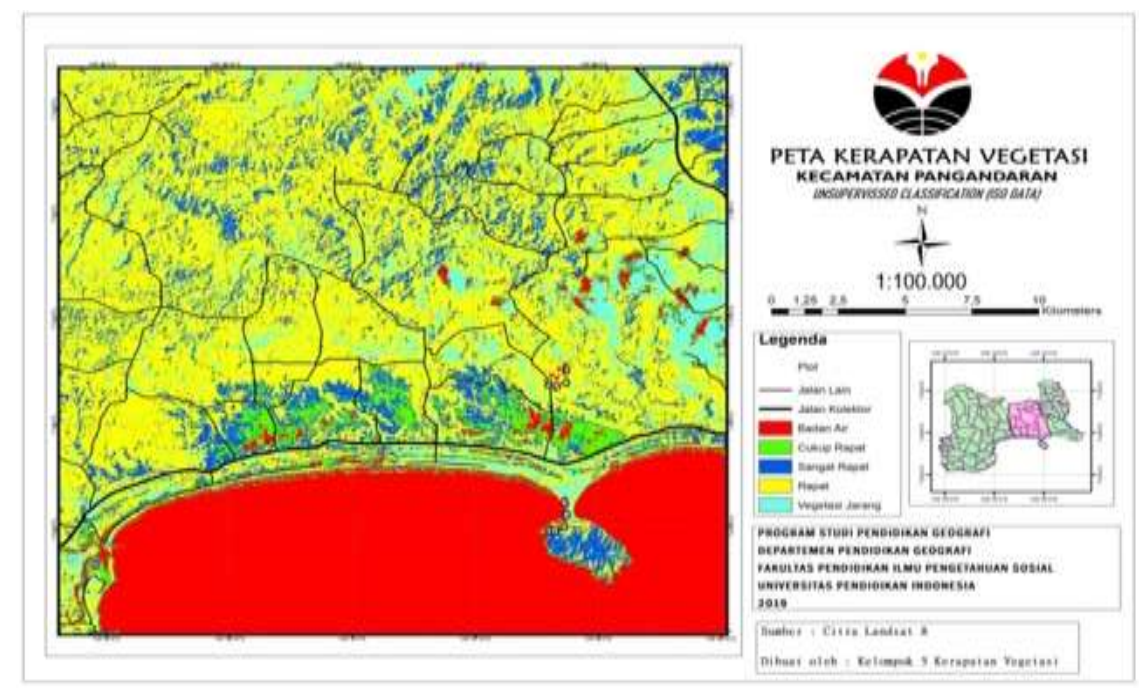

Gambar 1. Peta Hasil Interpretasi Metode Unsupervised Classification (IsoData 
Tabel 7. Lokasi Groundcheck

\begin{tabular}{|c|c|c|c|c|c|}
\hline PLOT & Koordinat & Jenis Vegetasi & Kerapatan & $\begin{array}{l}\text { Penggunaan } \\
\text { Lahan }\end{array}$ & Deskripsi \\
\hline 1 & $\begin{array}{l}7^{0} 38^{\prime} 54.7^{\prime \prime} \text { LS dan } \\
108^{0} 39^{\prime} 15.1^{\prime \prime} \mathrm{BT}\end{array}$ & $\begin{array}{l}\text { Pohon jati, pohon } \\
\text { kelapa, pohon } \\
\text { salak dan pohon } \\
\text { pisang }\end{array}$ & Cukup rapat & $\begin{array}{l}\text { Lahan } \\
\text { Campuran }\end{array}$ & $\begin{array}{l}\text { Berada di samping jalan } \\
\text { setapak dan pemukiman. }\end{array}$ \\
\hline 2 & $\begin{array}{l}7^{0} 39^{\prime} 03.1^{\prime \prime} \text { LS dan } \\
108^{0} 39^{\prime} 05.6^{\prime \prime} \mathrm{BT}\end{array}$ & $\begin{array}{l}\text { Pohon mangga } \\
\text { dan pohon pisang }\end{array}$ & $\begin{array}{l}\text { Vegetasi } \\
\text { jarang } \\
\text { (berada di } \\
\text { pinggir jalan) }\end{array}$ & $\begin{array}{l}\text { Pemukiman } \\
\text { dan Jalan Raya }\end{array}$ & $\begin{array}{l}\text { Berada di pinggir jalan, } \\
\text { banyak pemukiman dan } \\
\text { terdapat warung - } \\
\text { warung }\end{array}$ \\
\hline 3 & $\begin{array}{l}7^{0} 38^{\prime} 48,3^{\prime \prime} \text { LS dan } \\
108^{0} 39^{\prime} 23,1^{\prime \prime} \text { BT }\end{array}$ & $\begin{array}{l}\text { Pohon kelapa, } \\
\text { Pisang, Sirsak, dan } \\
\text { Nanas }\end{array}$ & $\begin{array}{l}\text { Vegetasi } \\
\text { jarang }\end{array}$ & $\begin{array}{l}\text { Lapangan } \\
\text { Voley }\end{array}$ & $\begin{array}{l}\text { Berada di dekat lapangan } \\
\text { voli dan ada kandang } \\
\text { kambing }\end{array}$ \\
\hline 4 & $\begin{array}{l}7^{0} 39^{\prime} 01,2 \text { " LS dan } \\
108^{0} 39^{\prime} 22,4^{\prime \prime} \text { BT }\end{array}$ & $\begin{array}{l}\text { Kayu jati dan } \\
\text { Kelapa }\end{array}$ & Cukup rapat & $\begin{array}{l}\text { Lahan } \\
\text { campuran }\end{array}$ & $\begin{array}{l}\text { Terdapat pohon- pohon } \\
\text { jati dan jati yang sudah } \\
\text { dipotong - potong }\end{array}$ \\
\hline 5 & $\begin{array}{l}7^{7} 39^{\prime} 07,6^{\prime} \text { LS dan } \\
108^{0} 39^{\prime} 12^{\prime \prime} \mathrm{BT}\end{array}$ & $\begin{array}{l}\text { Pohon kelapa, } \\
\text { pohon jati, dan } \\
\text { jahe }\end{array}$ & Cukup rapat & $\begin{array}{l}\text { Kebun } \\
\text { Campuran }\end{array}$ & $\begin{array}{l}\text { Banyak terdapat pohon } \\
\text { jahe. }\end{array}$ \\
\hline 6 & $\begin{array}{l}7^{0} 41^{\prime} 58^{\prime \prime} \text { LS dan } \\
108^{0} 39^{\prime} 21^{\prime \prime} \mathrm{BT}\end{array}$ & Pohon kelapa & $\begin{array}{l}\text { Vegetasi } \\
\text { jarang }\end{array}$ & $\begin{array}{l}\text { Pantai, } \\
\text { bangunan }\end{array}$ & Berada di pesisir pantai \\
\hline 7 & $\begin{array}{l}7^{0} 42^{\prime} 11,4^{\prime \prime} \text { LS dan } \\
108^{0} 39^{\prime} 21,5^{\prime \prime} \text { BT }\end{array}$ & $\begin{array}{l}\text { Mangrove dengan } \\
\text { bunga berwarna } \\
\text { kuning, pohon } \\
\text { kelapa }\end{array}$ & $\begin{array}{l}\text { Vegetasi } \\
\text { jarang }\end{array}$ & $\begin{array}{l}\text { Pantai dan } \\
\text { bangunan }\end{array}$ & $\begin{array}{l}\text { Terdapat rusa, pohonnya } \\
\text { cukup besar-besar tetapi } \\
\text { jarak antar pohon } \\
\text { lumayan jauh }\end{array}$ \\
\hline 8 & $\begin{array}{l}7^{0} 42^{\prime} 18,8^{\prime \prime} \text { LS dan } \\
108^{0} 39^{\prime} 22,6 " \text { " BT }\end{array}$ & Pohon Beringin & Rapat & $\begin{array}{l}\text { Cagar alam } \\
\text { Pangandaran }\end{array}$ & $\begin{array}{l}\text { Banyak terdapat } \\
\text { binatang }\end{array}$ \\
\hline 9 & $\begin{array}{l}7^{0} 42^{\prime} 27,5^{\prime \prime} \text { LS dan } \\
108^{0} 39^{\prime} 19,4^{\prime \prime} \text { BT }\end{array}$ & Pohon Beringin & Sangat Rapat & $\begin{array}{l}\text { Cagar Alam } \\
\text { Pangandaran }\end{array}$ & \\
\hline 10 & $\begin{array}{l}7^{0} 42^{\prime} 33^{\prime \prime} \text { LS dan } \\
108^{0} 39^{\prime} 12,2^{\prime \prime} \text { BT }\end{array}$ & Pohon Beringin & Sangat Rapat & $\begin{array}{l}\text { Cagar alam } \\
\text { Pangandaran }\end{array}$ & $\begin{array}{l}\text { Terdapat Biawak, } \\
\text { monyet hitam dan } \\
\text { merupakan salah satu } \\
\text { jalan menuju Pantai } \\
\text { Pasir Putih }\end{array}$ \\
\hline
\end{tabular}

\section{Simpulan dan saran}

Kerapatan vegetasi berdasarkan NDVI dibagi menjadi 4 tingkatan yaitu Cukup Rapat, Rapat, Sangat Rapat, dan Vegetasi Jarang. Dengan menggunakan metode Unsupervised Classification Iso Data dapat diketahui bahwa tingkat vegetasi Rapat cukup mendominasi wilayah kecamatan Pangandaran, Vegetasi Jarang mendominasi pada bagian timur serta pada pinggir pantai, dan vegetasi Sangat Rapat ditemukan seperti pada wilayah Cagar Alam. Berdasarkan uji akurasi yang dilakukan, dapat ditemukan bahwa kesesuaian antara metode dengan data di lapangan yaitu sekitar $40 \%$ dan masuk dalam kategori rendah. Hal ini membuktikan bahwa metode Unsupervisde Classification Iso Data kurang tepat untuk digunakan dalam menganalisis kerapatan vegetasi.

Keadaan vegetasi cukup beragam, vegetasi yang banyak dijumpai pada lapangan yaitu Mangrove, Pohon Ketapang, dan Pohon Jati yang cukup terjaga dengan baik. Pembangunan RTH minimal harus berjumlah 30\% dari luas perkotaan, jika hal tersebut tidak dipenuhi maka keseimbangan ekosistem akan terganggu bahkan dapat menyebabkan kepunahan keanekaragaman hayati. Keadaan vegetasi dapat menentukan rencana pembangunan ruang terbuka hijau, dengan mengetahui jenis vegetasi maka akan diketahui pula tumbuhan yang harus diprioritaskan untuk pembangunan RTH. Kecamatan Pangandaran yang saat ini ditetapkan sebagai "Kawasan Wisata" membutuhkan RTH yang cukup banyak dan dengan ditambahnya RTH maka harus ada kesadaran dari pemerintah serta masyarakat untuk menjaga RTH yang telah ada.

Dalam mengkaji kerapatan vegetasi seharusnya disiapkan berbagai perencanaan sebaik mungkin. Disarankan untuk mengambil titik sampel lebih banyak atau minimal 30 titik, agar data yang dihasilkan 
dapat lebih beragam dan semakin banyak data maka akan semakin berpengaruh terhadap uji akurasi yang dilakukan. Pemerintah seharusnya memperbanyak RTH yang ada di kecamatan Pangandaran dan membuat pengawasan terhadap RTH yang telah ada agar keadaannya tetap terjaga dengan baik.

\section{Ucapan terima kasih}

Penelitian ini dapat diselesaikan berkat bimbingan dan dukungan dari berbagai pihak. pada kesempatan ucapan terima kasih disampaikan kepada kelompok penulis yang telah bekerja dengan maksimal, kepada Dosen Pembimbing Akademik dan rekan serta keluarga dari mahasiswa Pendidikan Geografi Universitas Pendidikan Indonesia angkatan 2018 yang senantiasa selalu mendoakan demi kelancaran penelitian.

\section{Daftar Rujukan}

Aftriana, C. V. (2013). Analisis Perubahan Kerapatan Vegetasi Kota Semarang Menggunakan Aplikasi Penginderaan Jauh. Geo-Image, 2(2).

Alizadeh, B., \& Hitchmough, J. (2019). A Review of Urban Landscape Adaptation to the Challenge of Climate Change. International Journal of Climate Change Strategies and Management, 11(2), 178-194.

Apriyanti, N. R., Nugroho, R. A., \& Soesanto, O. (2016). Algoritma K-Means Clustering Dalam Pengolahan Citra Digital Landsat. Klik-Kumpulan Jurnal Ilmu Komputer, 2(2), 110-122.

Ardhana, I. P. G. (2016). Dampak Laju Deforestasi Terhadap Hilangnya Keanekaragaman Hayati Di Indonesia. Jurnal Metamorfosa, 3(2), 120-129.

Cahyono, B. E., Febriawan, E. B., \& Nugroho, A. T. (2019). Analisis Tutupan Lahan Menggunakan Metode Klasifikasi Tidak Terbimbing Citra Landsat di Sawahlunto, Sumatera Barat. Teknotan: Jurnal Industri Teknologi Pertanian, 13(1), 8-14.

Faisal, M., \& Atmaja, D. M. (2019). Kualitas Air Pada Sumber Mata Air Di Pura Taman Desa Sanggalangit Sebagai Sumber Air Minum Berbasis Metode Storet. Jurnal Pendidikan Geografi Undiksha, 7(2), 7282.

Gowda, K., Sridhara, M. V, \& Rajan, S. (2008). Planning and Management of Parks and Green Areas: The Case of Bangalore Metropolitan Area. Management of Environmental Quality: An International Journal, 19(3), 270-282.

Kurniawan, I. S., Tapilouw, F. S., Hidayat, T., \& Setiawan, W. (2019). Keanekaragaman Aves di Kawasan Cagar Alam Pananjung Pangandaran. Titian Ilmu: Jurnal Ilmiah Multi Sciences, 11(1), 37-44.

Kusmana, C., \& Ningrum, D. R. P. (2016). Land Tipology and Mangrove Vegetation Condition of Bulaksetra, Pangandaran District, West Java Province Tipologi dan Kondisi Vegetasi Kawasan Mangrove Bulaksetra Kabupaten Pangandaran Provinsi Jawa Barat. Jurnal Silvikultur Tropika, 7(2).

Lufilah, S. N., Makalew, A. D., \& Sulistyantara, B. (2017). Pemanfaatan citra landsat 8 untuk analisis Indeks Vegetasi di DKI Jakarta. Jurnal Lanskap Indonesia, 9(1), 73-80.

McCord, J., McCord, M., McCluskey, W., Davis, P. T., Mcllhatton, D., \& Haran, M. (2014). Effect of Public Green Space on Residential Property Values in Belfast Metropolitan Area. Journal of Financial Management of Property and Construction, 19(2), 117-137.

Prasetyo, N. N., Sasmito, B., \& Prasetyo, Y. (2017). Analisis Perubahan Kerapatan Hutan Menggunakan Metode NDVI dan EVI Pada Citra Satelit Landsat 8 Tahun 2013 dan 2016 (Area Studi: Kabupaten Semarang). Jurnal Geodesi Undip, 6(3), 21-27.

Schwartz, F., Taff, B. D., Lawhon, B., \& VanderWoude, D. (2018). Mitigating Undesignated Trail Use: The Efficacy of Messaging and Direct Site Management Actions in An Urban-Proximate Open Space Context. Environmental Management, 62(3), 458-473.

Septiani, R., Citra, I. P. A., \& Nugraha, A. S. A. (2019). Perbandingan Metode Supervised Classification dan Unsupervised Classification terhadap Penutup Lahan di Kabupaten Buleleng. Jurnal Geografi: Media Informasi Pengembangan Dan Profesi Kegeografian, 16(2), 90-96.

Sinaga, S. H., Suprayogi, A., \& Haniah, H. (2018). Analisis Ketersediaan Ruang Terbuka Hijau dengan Metode Normalized Difference Vegetation Index dan Soil Adjusted Vegetation Index Menggunakan Citra Satelit Sentinel-2a (Studi Kasus: Kabupaten Demak). Jurnal Geodesi Undip, 7(1), 202-211.

Thorne, J. H., Santos, M. J., \& Bjorkman, J. H. (2013). Regional Assessment of Urban Impacts on Landcover and Open Space Finds A Smart Urban Growth Policy Performs Little Better Than Business as Usual. PloS One, 8(6).

Threlfall, C. G., Ossola, A., Hahs, A. K., Williams, N. S., Wilson, L., \& Livesley, S. J. (2016). Variation in Vegetation Structure and Composition Across Urban Green Space Types. Frontiers in Ecology and Evolution, 66(4). 
Tufaila, M., Karim, J., \& Alam, S. (2012). Pemanfaatan Penginderaan Jauh dan Sistem Informasi Geografis untuk Pemetaan Bentuklahandi DAS Moramo. Jurnal Agroteknos, 2(1), 9-20.

Wulansari, H. (2018). Uji Akurasi Klasifikasi Penggunaan Lahan Dengan Menggunakan Metode Defuzzifikasi Maximum Likelihood Berbasis Citra Alos Avnir-2. BHUMI: Jurnal Agraria Dan Pertanahan, 3(1), 98-110. 